\title{
THE INDUCTION OF INVOLUTION IN THE MALE REPRODUCTIVE SYSTEM BY TREATMENT WITH ADRENOCORTICOTROPIN ${ }^{1}$
}

\author{
BURTON L. BAKER, MARJORIE A. SCHAIRER, DWIGHT J. INGLE \\ AND CHOH HAO LI \\ Department of Anatomy, University of Michigan Medical School, Ann Arbor; \\ Research Laboratories, The Upjohn Company, Kalamazoo, Michigan, \\ and Institute of Experimental Biology, University of California, \\ Berkeley \\ SIXTEEN FIGURES
}

Regressive changes in the reproductive system of both sexes have been recognized for some time as being among the important anatomical effects brought about by subjection of animals to various types of stress (Selye, '46) such as starvation and exposure to low oxygen tension (Dalton, Jones, Peters and Mitchell, '45). One generally accepted explanation for this outcome is defective gonadotropic stimulation by the anterior hypophysis. Since it has been established that stress causes an accelerated production of adrenocorticotropin by the anterior hypophysis (Sayers and Sayers, '48), it is of interest to know whether the metabolic action of adrenocorticotropin might be related to the reduced synthesis or secretion of gonadotropin. This becomes a possibility if it can be demonstrated that adrenocorticotropin may cause atrophy of the gonads or interfere with their function. In view of the current widespread interest of clinical investigators in the therapeutic applications of adrenocorticotropin, more knowledge concerning its action on the reproductive system is to be desired.

\footnotetext{
${ }^{1}$ Aided in part by a grant from the Division of Research Grants and Fellow-
} ships of the United States Public Health Service (C-768). 
Studies reported previously of the action of adrenocorticotropic preparations on the male reproductive system have indicated a stimulating action. Davidson and Moon ('36) and Davidson ('37) employed a preparation extracted from sheep hypophyses and found that treatment of immature castrated or hypophysectomized-castrated rats caused a considerable increase in weight of the prostate and seminal vesicles when these organs were weighed together. Similar results were obtained by Nelson ('41) who interpreted his observations to mean that the adrenal cortex of the rat may be stimulated to produce androgens. If adrenocorticotropin stimulates the reproductive system then it becomes more difficult to explain the atrophy which occurs in it during stress when the level of endogenous adrenocorticotropin may be elevated.

Since the preparations used by these workers were not shown to be chemically pure, we have sought to duplicate their findings with an adrenocorticotropic preparation which has been demonstrated to be a homogeneous protein ( $\mathrm{Li}$, Evans and Simpson, '43). Li and Evans ('47) have reported briefly that this hormone depressed the growth rate of the testes, seminal vesicles, prostate and Cowper's glands when injected into 26-day-old rats for 30 days. However, they observed no effect from the treatment of adult rats with $1 \mathrm{mg}$ daily for 15 days. The purpose of this report is to show that, if the dosage is increased or period of injection prolonged, actual regression of parts of the male reproductive system in adult rats may be induced with adrenocorticotropin.

\section{MATERIAIS AND METHODS}

This presentation is part of a general study of the effect of adrenocorticotropin on the anatomy of the body and the experimental procedures employed on the rats used in this study have been described previously (Baker, Ingle, Li and Evans, '48). In order to insure adequate nutrition all animals were force-fed. This study is based on specimens removed from 12 non-operated rats which were fed a high fat diet, two rats 
fed a high carbohydrate diet and two which were maintained on a high protein diet. All of these rats received $1 \mathrm{mg}$ of adrenocorticotropin per day for 21 days. One rat on each diet received $3 \mathrm{mg}$ of adrenocorticotropin daily for 21 days. Two rats on the fat diet, two on the protein and 4 on the carbohydrate diet received $8 \mathrm{mg}$ of adrenocorticotropin daily for 10 days. In addition, three castrated rats on the fat diet were given $1 \mathrm{mg}$ of adrenocorticotropin daily for 21 days. For each animal receiving the hormone there was one control rat which was injected with physiological salt solution.

The testes and seminal vesicles of most of the animals were fixed in Bouin's fluid and stained with hematoxylin and eosin and the Masson procedure. For the organs removed from 10 treated rats and their controls, these procedures were supplemented by fixing pieces in Carnoy's fluid, sections of which were stained with eosin and methylene blue (citric acid-- disodium phosphate buffer, $\mathrm{pH} 4.3$ and 4.8), Best's carmine and the Hotchkiss ('48) periodic acid-leucofuchsin techniques. Staining for glycogen was controlled by saliva digestion. Slides showing basophilia were digested with $0.1 \%$ crystalline ribonuclease in veronal buffer at $\mathrm{pH} 9.8$ for $1 \frac{1}{2}$ hours at $52^{\circ} \mathrm{C}$. for the demonstration of ribonucleic acid. Pieces fixed in $80 \%$ alcohol were used for the Gomori ('39) procedure for alkaline phosphatase with sodium glycerophosphate serving as a substrate. Incubation was carried out for $6 \frac{1}{2}$ hours at $37^{\circ} \mathrm{C}$. at $\mathrm{pH} 9.7$ for the testes and 9.5 for the seminal vesicles. Frozen sections of samples fixed in $10 \%$ formalin in $0.9 \%$ $\mathrm{NaCl}$ were stained with Sudan red and Sudan black B.

\section{RESULTS}

\section{(a) Non-operated animals}

Testes. One testis was weighed at autopsy from each of 10 rats on the high fat diet which received $1 \mathrm{mg}$ of adrenocorticotropin daily for 21 days. The mean weight of the testes was $1504 \pm$ standard deviation $41 \mathrm{mg}$ as compared with $1731 \pm 157 \mathrm{mg}$ for the 10 controls. The histological changes 
accompanying this slight reduction in testicular weight were not striking. Although there may have been some occasional reduction in diameter of the seminiferous tubules, in most instances they were of normal size. Spermatozoa were abundant and areas of active cell division were found in the germinal epithelium. Thus, it may be inferred that gametogenesis was not impaired seriously by the action of adrenocorticotropin.

On the other hand, it appeared that the production of androgen by the testis was reduced. This is deduced from a reduction in number of the Leydig cells which resulted from treatment with adrenocorticotropin (figs. 1 and 2). These cells are regarded generally as being the source of the male sex hormone. The magnitude of this change in structure varied among the adrenocorticotropin-treated rats, but was definitely significant in about $80 \%$ of these animals. It bore no certain relationship to diet and was produced both by injecting 1 or $3 \mathrm{mg}$ of adrenocorticotropin daily for 21 days and $8 \mathrm{mg}$ daily for the shorter period of 10 days.

Attempts to reveal histochemical changes in the interstitial tissue were not significantly successful. Alkaline phosphatase, which is normally present in the basement membrane of the seminiferous tubules, walls of the small interstitial blood vessels and nucleoli of the Leydig cells, was still found in these locations after treatment with adrenocorticotropin. The activity of this enzyme varied in different cases but the nature of the Gomori procedure does not enable one to attach great significance to small differences which it may reveal. Staining of frozen sections with Sudan black B showed that lipid material was present after treatment with adrenocorticotropin. In several instances the total lipid revealed by this procedure appeared to be somewhat less than in the controls but our preparations were not convincing on this point.

Seminal vesicles. The secretory epithelium of the control rats possessed several interesting cytological features. Basophilia (shown by digestion with ribonuclease to be due to 
the presence of ribonucleoprotein in the cytoplasm) was concentrated densely around the nucleus in the basal part of the cell (fig. 13). It was found also at the sides of the large supranuclear negative image of the Golgi apparatus, and sometimes at the secretory pole of the cell. Eosinophilic secretory granules were scattered throughout the Golgi region and above it (fig. 13), and appeared in the lumen of the gland close to the epithelium. At the deepest portion of the secretory recesses, glycogen occurred in significant amounts in some small cells basal to the columnar epithelium (fig. 12). These appeared to be flattened basal cells previously described by Moore, Hughes and Gallagher ('30). Also, minute granules of glycogen were distributed more sparsely in the supranuclear region of some columnar cells. Alkaline phosphatase showed extreme activity in the connective tissue supporting the parenchyma (fig. 15). Except for the granules of glycogen mentioned above, the seminal vesicle epithelium gave a negative reaction to the periodic acid-leucofuchsin procedure (fig. 7). However, the connective tissue adjacent to the epithelium re-colorized the fuchsin. Very little lipid was found in the epithelium. The nuclei of the columnar epithelial cells were characterized by one or more large nucleoli and sparsely dispersed chromatin. The eosinophilic secretion of the lumen contained little or no glycogen and was negative or very faintly positive to the periodic acid-leucofuchsin procedure.

In all but two of the 27 rats treated with adrenocorticotropin, the seminal vesicles were smaller than those of the control animals (figs. 3 and 4). (In the two exceptional cases there was evidence that the specimens from control and ex. perimental rats had been mixed inadvertently.) This reduction in size and in the amount of secretion contained within the glands was observed readily at autopsy. Microscopically the epithelium showed less basophilia, a smaller Golgi region and fewer secretory granules (fig. 14). The nucleolus became less prominent and the basophilic material of the nu- 
cleus assumed a more coarsely granulated appearance. As compared with the seminal vesicles of the control rats, there was no great change in the alkaline phosphatase or leucofuchsin staining reaction of the neighboring connective tissue.

Large granules of glycogen appeared throughout the cytoplasm of numerous cells (figs. 11 and 12). Whether this represented a true increase in amount or only a greater concentration because of the accompanying decrease in cellular size could not be ascertained. Six rats were castrated and their seminal vesicles eompared with those of 6 non-operated rats in order to find out if this change in glycogen was due to the direct glycogenic action of adrenocorticotropin or to the loss of normal testicular function. Similar large granules formed in the epithelium so that the increase in glycogen content after treatment with adrenocorticotropin was not a special direct response to the action of this hormone. Thus, in so far as histological changes have been described in the seminal vesicles after castration (Moore, Hughes and Gallagher, '30), those which followed treatment with adrenocorticotropin were similar except less severe.

Coagulating gland. In specimens from control animals, the apical cytoplasm of the epithelial cells was dense, of reticular form and included faintly stained granules after staining with the Masson technique. In contrast, fixation in aqueous fluids followed by alcoholic dehydration resulted in frequent vacuolation of the subnuclear cytoplasm (fig. 9). This vacuolation could not be explained by the removal of glycogen or lipid because our procedures did not reveal the presence of significant quantities of either of these substances. However, the intensely positive reaction rendered to the periodic acid-leucofuchsin procedure (fig. 8) showed this gland to be concerned primarily with the production of a secretion of high molecular weight containing carbohydrate, this probably being a glycoprotein (Hotchkiss, '48). The basal region of the epithelial cells of many lobules, particularly those containing secretion, stained diffusely with the fuchsin. This latter finding sug- 
gested that the basal vacuolation resulted from the removal of a carbohydrate-containing substance. In addition to this diffuse staining with fuchsin, discrete deep purple-violet granules were present in the cytoplasm. Finally, the luminal secretion stained intensely.

Little if any cytoplasmic basophilia was observed. The connective tissue subjacent to the parenchyma exhibited intense alkaline phosphatase activity (fig. 16). The nucleus occupied a more central position in many cells than was true of the seminal vesicle.

In contrast to the marked reduction in size of the seminal vesicle caused by adrenocorticotropin, the changes induced in the coagulating gland were comparatively slight. In only a few cases, which were treated with high doses of the hormone, were the epithelial cells smaller and the amount of secretion reduced (figs. 9 and 10).

\section{(b) Castrated animals}

In view of previous reports that adrenocorticotropin stimulates the adrenal cortex to secrete androgens, we sought to verify this conclusion by injecting adrenocorticotropin into three castrated rats whose seminal vesicles were completely atrophic due to removal of the testicular source of androgens. Three castrated rats served as controls. As shown by figures 5 and 6 the seminal vesicles in these animals were not stimulated. Thus, secretion of male sex hormone by the adrenal cortex was either not induced by this pituitary hormone, or if it was, other adrenocortical hormones nullified its effects.

\section{DISCUSSION}

Earlier investigators (Davidson, '37; Nelson, '41) who secured evidence of stimulation of the reproductive system by the injection of adrenocorticotropic preparations, employed immature animals. In contrast, our experiments were carried out on adult rats. This difference in the age of the experimental animals used may explain why we observed sup- 
pression of the reproductive system instead of stimulation. Pertinent to this problem are the numerous other studies which have been made of the maintenance of accessory reproductive organs in castrated rats. The continued growth after gonadectomy of the accessory reproductive organs in immature male rats, but not in adult rats, suggests that the adrenal cortex of only the former possesses the capacity to secrete androgens (Parkes, '45). Other information also indicates that the adrenal cortex may perform an androgenic function in other forms. Androgenic compounds have been isolated from adrenal glands (Reichstein, '36). The masculinizing effect of human adrenocortical neoplasms is well known. Finally, the accelerated release of androgens from human adrenals under stimulation by adrenocorticotropin has been inferred from the increased excretion of 17-ketosteroids observed under such treatment (Mason, Power, Rynearson, Ciaramelli, Li and Evans, '48; Forsham, Thorn, Prunty and Hills, '48).

In the face of this evidence it seems best to explain our findings on the basis of stimulation of the adrenal cortex to produce steroids having physiological actions similar to those of the C-11 oxygenated group. The suppressing action of adrenocorticotropin on the male reproductive system may be related to the metabolic action of these substances. It is becoming increasingly evident that treatment of rats with adrenocorticotropin prepared by the method of Li, Evans and Simpson ('43) causes secretion by the adrenal cortex of the C-11 oxygenated steroids or of compounds related to them in their physiological effects. These substances act chiefly on organic metabolism. Analysis of the urine of many of the rats whose organs were used in this study demonstrated that a negative nitrogen balance was set up by the action of adrenocorticotropin (Ingle, Prestrud, Li and Evans, '47). This finding suggests that a deficient supply of amino acids was available to various glands for the synthesis of protein secretions, such as gonadotropin by the anterior hypophysis. There- 
fore, it seems probable that adrenocorticotropin caused an involution of the reproductive system indirectly by interfering with the capacity of the hypophysis to stimulate the gonads. The slight reduction in testicular weight and, particularly, the reduction in the number of the Leydig cells shows that intrinsic gonadotropin, particularly the interstitial cell-stimulating factor, was not normally effective. A similar non-availability of protein precursors may also explain in part the involution of the seminal vesicles since the secretion produced by this gland is albuminoid in character. Nevertheless, deficient androgen production by the testicular Ieydig cells must have been chiefly responsible for epithelial atrophy in these glands.

Finally, future investigations dealing with the effects of various types of stresses on the reproductive system must be concerned with the possible involvement of adrenocorticotropin in the induction of these changes. In the past, attention has been given only to pituitary gonadotropin, the amount of this hormone in the hypophysis having been studied during starvation. Werner ('39) reported a reduction, whereas Marrian and Parkes ('29), and Maddock and Heller ('47) found no change. More recently, by assaying in hypophysectomized rats the hypophyses from underfed rats, Rinaldini ('49) has been able to demonstrate a 4-fold increase in gonadotropic content due to this type of stress. Maddock and Heller and Rinaldini agree that chronic starvation interferes with release of this hormone from the hypophysis, the former authors stating that, in effect, production is impaired also. It should be noted that parabiotic union of underfed with normal rats caused interruption of the estrous cycle in the normal rat, indicating the secretion of some interfering substance (adrenocorticotropin?) by the underfed mate (Rinaldini, '49). Thus, most workers would concur that synthesis of gonadotropin is suppressed by inanition. The comparative importance of adrenocorticotropin and inanition per se in causing a reduced production of gonadotropin remains for future clarification. 


\section{SUMMARY}

The male reproductive system was studied from 27 intact adult male rats and three eastrated rats which had received adrenocorticotropin in doses ranging from 1 to $8 \mathrm{mg}$ a day. The treatment caused a slight reduction in weight of the testes with atrophy of the Leydig cells in about $80 \%$ of the cases. There followed reduction in size of the seminal vesicles with the coagulating gland being affected less. The histological changes observed in the seminal vesicles were similar to those observed after castration, and included loss of cytoplasmic basophilia and increase in the concentration of glycogen. It was felt that these results were a reflection of the metabolic effects of the C-11 oxygenated steroids, which are released from the adrenal cortex under the influence of adrenocorticotropin and which set up a negative nitrogen balance.

The coagulating gland of the normal rat differed from the seminal vesicle in that its secretory epithelium possessed little cytoplasmic basophilia and produced a secretion which stained intensely with the periodic acid-leucofuchsin procedure indicating that it was a substance of high molecular weight containing carbohydrate.

\section{LITERATURE CITED}

BaKer, B. L., D. J. Ingle, C. H. Li aND H. M. Evans 1948 The effect on liver structure of treatment with adrenocorticotropin under varied dietary conditions. Am. J. Anat., 82: 75-103.

Dalton, A. J., B. F. Jones, V. B. Peters and E. R. Mitchell 1945 Organ changes in rats exposed repeatedly to lowered oxygen tension with reduced barometrie pressure. J. Nat. Can. Inst., 6: 161-185.

Davidson, C. S. 1937 Effect of adrenotropie extract upon the aceessory reproductive organs of eastrated rats. Proc. Soc. Exp. Biol. and Med., 36: 703-705.

Davidson, C. S., AND H. D. Moon 1936 Effect of adrenocorticotropie extracts on accessory reproductive organs of castrate rats. Proc. Soc. Exp. Biol. and Med., 35: 281-282.

Forsham, P. H., G. W. Thorn, F. T. G. Pruntt and A. G. Hills 1948 Clinieal studies with pituitary adrenocorticotropin. J. Clin. Endoer., 8: 1566.

Gomori, G. 1939 Microtechnical demonstration of phosphatase in tissue sections. Proc. Soc. Exp. Biol. and Med., 42: 23-26. 
Hotchkiss, R. D. 1948 A microchemical reaction resulting in the staining of polysaccharide structures in fixed tissue preparations. Arch. Bioehem., 16: 131-141.

Ingle, D. J., M. C. Prestrud, C. H. Li and H. M. Evans 1947 The relationship of diet to the effect of adrenocorticotrophic hormone upon urinary nitrogen, glucose and electrolytes. Endocr., 41 : 170-176.

LI, C. H., AND H. M. Evans 1947 The properties of the growth and adrenocorticotropic hormones. Vitamins and Hormones, 5: 197-232. Academic Press, Inc., New York.

Li, C. H., H. M. Evans and M. E. Simpson 1943 Adrenocorticotropic hormone. J. Biol. Chem., 149 : 413-424.

MADDock, W. O., AND C. G. HelleR 1947 Dichotomy between hypophyseal content and amount of circulating gonadotrophins during starvation. Proc. Soe. Exp. Biol. and Med., 66: 595-598.

Marrian, G. F., AND A. S. Parkes 1929 The effect of anterior pituitary preparations administered during dietary anoestrus. Proc. Roy. Soc., Series B, London, 105: 248-258.

Mason, H. L., M. H. Power, E. H. Rynearson, L. C. Ciarameli, C. H. Li and H. M. Evans 1948 Results of administration of anterior pituitary adrenocorticotropic hormone to a normal human subject. J. Clin. Endoer., 8: 1-14.

Moore, C. R., W. Hughes and T. F. Gallagher 1930 Rat seminal-vesicle eytology as a testis-hormone indicator and the prevention of castration changes by testis-extract injection. Am. J. Anat., 45: 109-136.

Nelson, W. O. 1941 Production of sex hormones in the adrenals. Anat. Rec., 81: (Suppl.) 97.

PARKEs, A. S. 1945 The adrenal-gonad relationship. Physiol. Rev., 25: 203-254. Reichstein, T. 1936 "Adrenosteron." Über die Bestandteile der Nebennierenrinde II, Helv. Chim. Acta, 19: 223-225.

RINALDINI, L. M. 1949 Effect of chronic inanition on the gonadotrophic content of the pituitary gland. J. Endocr., 6: 54-61.

Sayers, G., AND M. A. SAyers 1948 The pituitary-adrenal system. Recent Progress in Hormone Research, 2: 81-115. Academic Press, Inc., New York.

SELYe, H. 1946 The general adaptation syndrome and the diseases of adaptation. J. Cin. Endocr., 6: 117-230.

WERNER, S. C. 1939 Failure of gonadotropic function of the rat hypophysis during chronic inanition. Proc. Soc. Exp. Biol, and Med., 41: 101-105. 


\section{PLATE 1}

\section{EXPLANATION OF FIGURES}

1 Testicular interstitial tissue. Control for figure 2. The Leydig cells are elustered around the capillaries. Irom hematoxylin and Masson. $\times 360$.

2 Testicular interstitial tissue, $3 \mathrm{mg}$ of adrenocorticotropin daily for 21 days, high carbohydrate diet. Leydig cells are fewer and smaller. Technique as in figure 1 .

3 Seminal vesicle, control for figure 4 . Iron hematoxylin and Masson. $\times 95$.

4 Seminal vesicle, $8 \mathrm{mg}$ of adrenocorticotropin daily for 10 days, high fat diet. The epithelium is atrophic. Technique as in figure 3.

5 Seminal vesicle, eastrated rat, control for figure 6. Hematoxylin and eosin. $\times 150$.

6 Seminal vesicle, castrated rat, $1 \mathrm{mg}$ of adrenocorticotropin daily for 21 days, high fat diet. There is no evidence of stimulation by audrogens. Technique as in figure $5 . \times 150$.

7 Seminal vesicle, periodic acid-leucofuchsin. The epithelium is practically negative as is the secretion above. The connective tissue basal to the epithelium is stained. $\times 250$.

8 Coagulating gland, periodic acid-leucofuchsin. The secretion is stained intensely. The epithelium stains diffusely and also contains intensely stained granules. $\times 250$. 

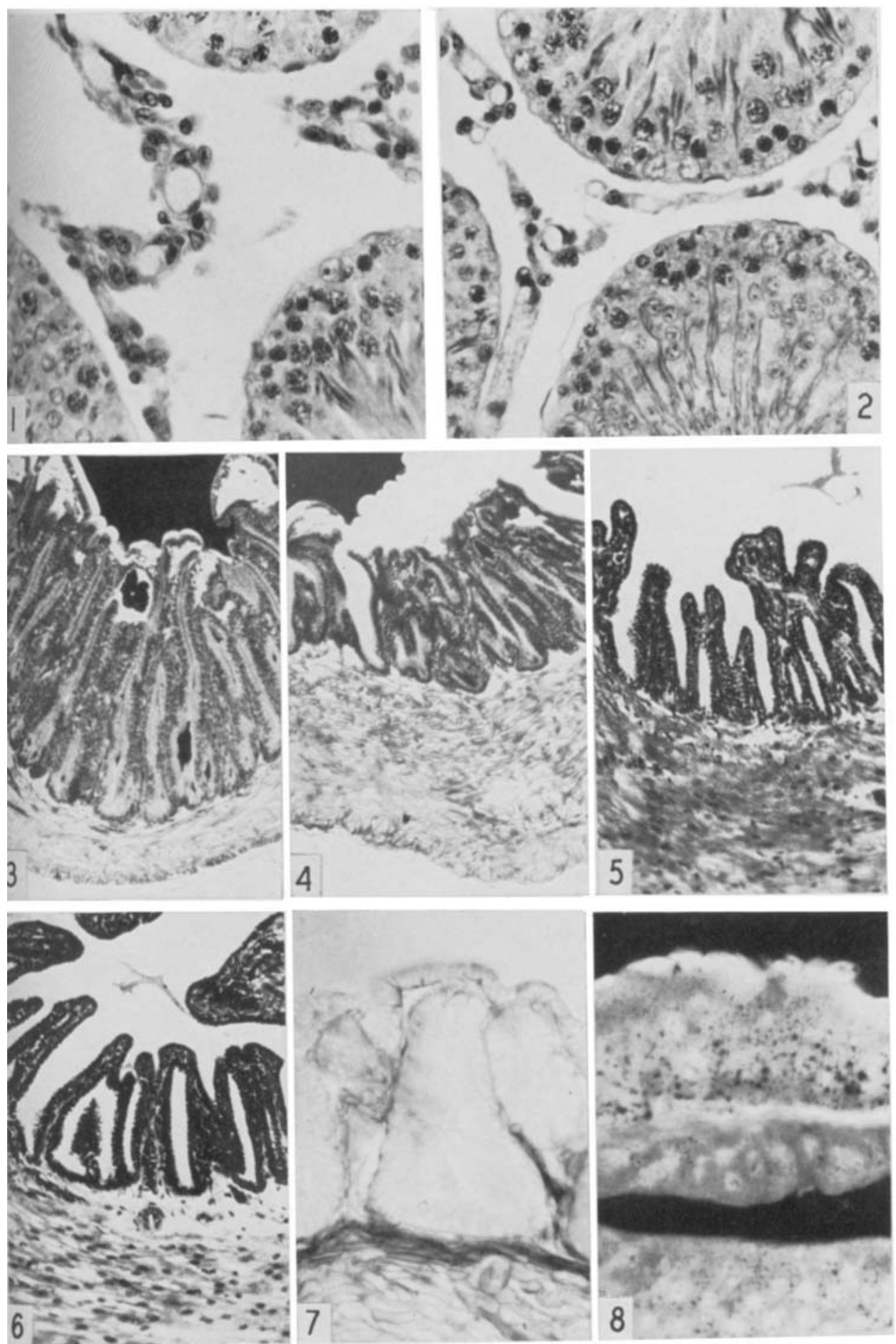


\section{PLATE 2}

\section{EXPLANATION OF FIGURES}

9 Coagulating gland, control for figure 10. The cytoplasm is dense apically and vacuolated basally. Bouin's fixation, iron hematoxylin and Masson. $\times 360$.

10 Coagulating gland, $3 \mathrm{mg}$ of adrenocorticotropin daily for 21 days, high carbohydrate diet. The epithelium is atrophic. This is the most extreme case of atrophy observed. Technique as in figure 9 .

11 Seminal vesicle, control for figure 12. No glycogen is visible. Carnoy fixation; Best's carmine. $\times 1000$.

12 Seminal vesicle, $1 \mathrm{mg}$ of adrenocorticotropin daily for 21 days, high fat diet. Granules of glycogen are present throughout the cytoplasm. The dark mass at the lower side of the epithelium is a basal cell loaded with glycogen. Technique as in figure 11.

13 Seminal vesicle, control for figure 14. Basophilia is distributed throughout the basal portion of the cells. Many eosinophilic granules are present in the supranuclear cytoplasm. Carnoy fixation; eosin and methylene blue. $\times 1000$.

14 Seminal vesicle, $1 \mathrm{mg}$ of adrenocorticotropin daily for 21 days, high fat diet. Secretory granules and cytoplasmic basophilia are gone, cells are smaller and nucleoli less prominent. Technique as in figure 13.

15 Seminal vesicle. Alkaline phosphatase activity is intense in the connective tissue adjacent to the epithelium. Gomori procedure. $\times 220$.

16 Coagulating gland. Alkaline phosphatase is distributed similarly to that in the seminal vesicle. Gomori technique. $\times 220$. 
BAKER, SCHAIRER, INGLE AND
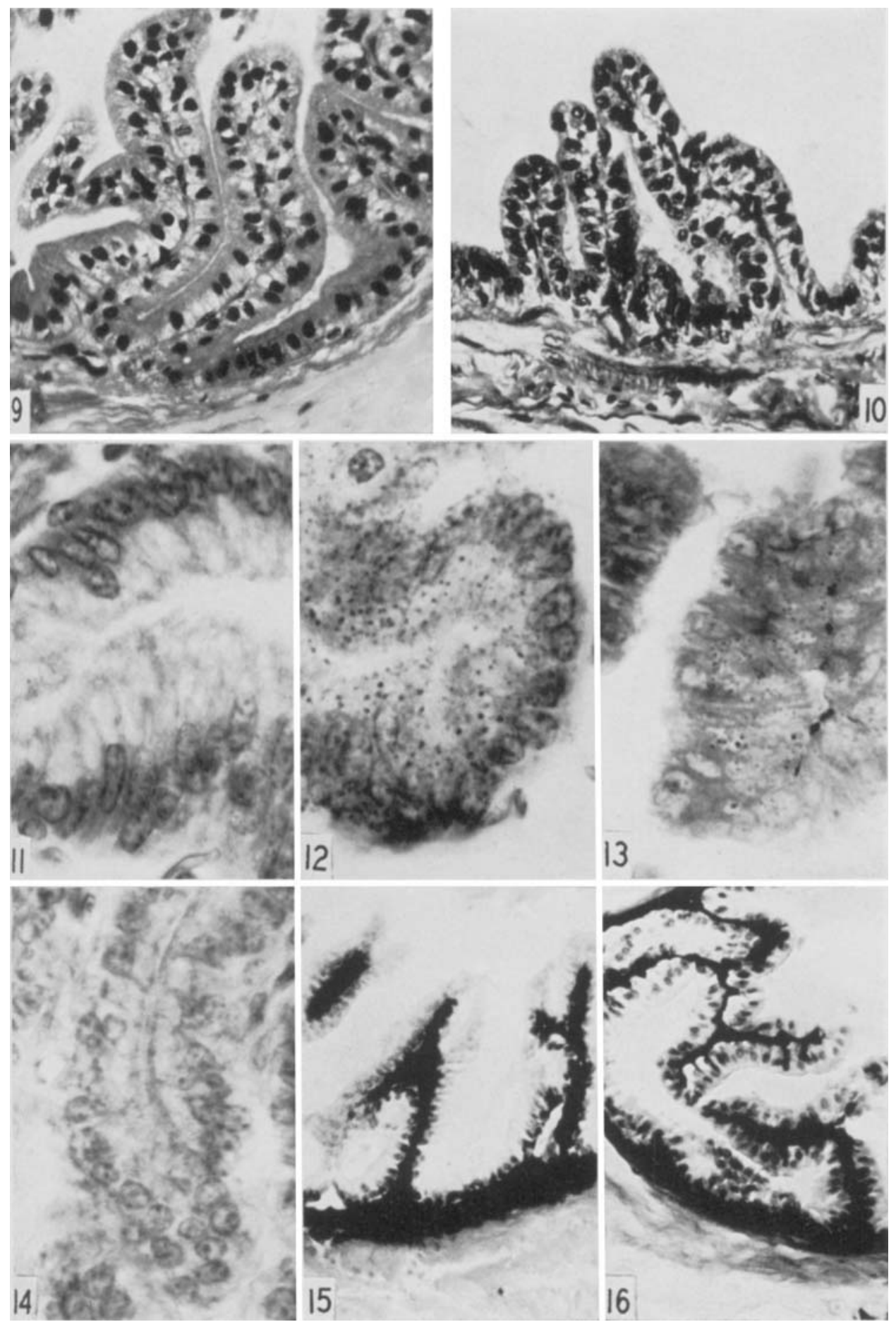